\title{
Gilad Sorek*
}

\section{Competition and Product Choice in Option Demand Markets}

DOI 10.1515/bejeap-2015-0164

Published online March 15, 2016

Abstract: This work presents the first analysis of competition through horizontal and vertical differentiation in option demand markets, which are common in the health-care sector. I studied two alternative market structures: (a) a "pure" option demand market where medical providers sell insurance directly to consumers and (b) a public insurance regime where the public insurer bargains over prices with providers before bundling both products under a single insurance policy. I show that (a) product choices in option demand markets differ greatly from those in respective spot markets and (b) bundling medical products under a single insurance policy alters product choices and equilibrium prices in a way that does not benefit consumers.

Keywords: medical insurance, option demand, product differentiation JEL Classification: I11, I13, L1

\section{Introduction}

Consumers typically buy health insurance before knowing which medical product they will eventually need. Hence, they may prefer an insurance policy that gives them an option to utilize multiple differentiated providers upon the emergence of a specific medical need. ${ }^{1}$ However, the incidence of such option demand depends crucially on the degree of horizontal differentiation of products: in the absence of horizontal differentiation, all products of equal quality are perfect substitutes, and in the case of quality (vertical) differentiation, the product with superior quality dominates all others. However, to my knowledge, the determination of horizontal differentiation in option demand markets has not yet been studied. This work is the first attempt to fill this gap in the literature.

1 See Capps, Dranove, and Satterthwaite (2003) for a detailed introduction to option demand markets.

*Corresponding author: Gilad Sorek, Economics Department, Auburn University, 0334 Haley Center, Auburn, AL 36849, USA, E-mail: gms0014@auburn.edu 
A large body of theoretical and empirical research has studied markets for differentiated medical products under insurance sales. ${ }^{2}$ Apart from a few exceptions, all theoretical works have assumed that consumers know their preferred medical product before becoming sick (see Barros and Martinez-Giralt 2002; Bardey and Bourgeon 2011; Katz 2011). This approach was criticized by Capps, Dranove, and Satterthwaite (2003), who emphasized the notion of option demand and its significance to health-care market analysis:

prior work on hospital pricing has been based on an analogy with conventional markets in which individual consumers make their purchase at the time they know their needs. This is inappropriate for hospital services. With the prevalence of managed care, almost all consumers select among alternative bundles of providers not at the ex-post stage, but at the ex-ante stage before they know their diagnoses. (p. 740)

The works of Town and Vistnes (2001) and Capps, Dranove, and Satterthwaite (2003) on competition and market power in option demand markets prompted a growing body of empirical research on the topic. ${ }^{3}$ Nonetheless, the theoretical literature on competition in option demand markets remains scarce and focused on the vertical relations between insurers and providers. Among the few examples are the works of Gaynor and Ma (1996), Ma (1997), Gal-Or (1997), Lyon (1999) and Douven et al. (2014). These studies, as with all the other aforementioned studies, assumed exogenous horizontal differentiation. In particular, researchers employing Hotelling's spatial setup assumed that providers are located at the two ends of the market. This assumption may have been inspired by the maximal-differentiation principles established for spot market competition (see d'Aspremont, Gabszewicz, and Thisse 1979; Economides 1989), as proposed by Gaynor and Town (2012):

where firms locate on a line, it seems evident that firms will have an incentive to locate as far apart from each other as possible (at the ends of the line), rather than nearby (in the middle). If they locate in the middle, the products are identical... Thus firms will engage in fierce product quality competition... If firms are located at the ends of the line, then each firm will be considerably more attractive to consumers located very close to it. This will dampen quality competition. (p. 575)

I show here that this conjecture does not hold in option demand markets and that product choices in these markets generally differ from those made in spot

2 Horizontal differentiation is commonly interpreted in terms of the geographic distance between providers or differences in product characteristics, e. g., hospitals' area of specialization or differential effectiveness of alternative pharmaceuticals within therapeutic categories. See Bardey, Cantac, and Lozachmeur (2012) for more detailed examples.

3 See Gaynor, Ho, and Town (2015) for a comprehensive review. 
markets. More specifically, in this work, I present a comparative analysis of two alternative option demand markets. The first market has the simplest possible structure: each medical provider is selling an insurance policy for its own product by setting an option price, i. e., an insurance premium, and consumers can buy insurance from one or both providers.

I refer to this setup as the benchmark option demand market model or a "pure" option demand market because it is not distorted by any of the structural features of real insurance markets. The formal presentation of the benchmark model can be equivalently interpreted as involving perfectly competitive insurers pricing and selling separate insurance policies for each single product. In the second option demand market to be analyzed here, a single public insurer bargains with providers over prices on behalf of consumers before bundling their products under a single insurance policy. Such dominant public insurance plans, as Medicare in the USA, are common in developed economies. This extension aims to demonstrate how more realistic option demand market may perform relative to the benchmark model.

On the demand side, I assume the conventional preferences for which d'Aspremont, Gabszewicz, and Thisse (1979) obtained the maximum differentiation principle in spot market competition, except for introducing consumers' uncertainty about their future medical needs; that is, when buying insurance, consumers do not know their future location on the medical conditions/products line. For the benchmark model, I find that competition in simultaneous product choices yields efficient quality provision and horizontal differentiation (providers locate at the first and third quartiles of the product line) and quality provision. ${ }^{4}$ In previous works, Ma and Burgess (1993) find insufficient investment in quality for spot market spatial competition, Lyon (1999) and Katz (2011) find that under indemnity insurance investment in quality may be excessive or efficient, respectively.

Competition under sequential product choices in the benchmark model yields asymmetric equilibrium, with the leader located in the middle and the follower located close to the market end. Sequential entry yields lower differentiation and higher surplus for the market leader compared with the equilibrium under simultaneous moves. Nevertheless, although sequential entry implies insufficient differentiation and a niche product property for the follower,

4 It is well known that alternative modeling of demand could also alter the principle of maximum differentiation, e. g., different transportation costs (Economides 1986) and preference distribution (Anderson, Goeree, and Ramer 1997), or uncertainty with respect to quality (Bester 1998). However, in the present analysis, option demand not only mitigates the incentive for maximal differentiation but also supports efficient location choices. 
it still yields higher expected surplus for consumers as a result of more intense price competition. ${ }^{5}$ By contrast, Tabuchi and Thisse (1995) showed that for the respective spot market, the maximal differentiation principle holds under sequential entry.

The analysis of the option demand market under a public insurance regime yields similar qualitative results while highlighting the role of bundling medical products through health insurance policies in softening the competition between medical providers. In particular, I find that under public insurance, horizontal differentiation is excessive, prices are higher and quality provision is lower compared with the benchmark model. Consequently, consumers are worse off than in the benchmark model. This outcome occurs despite the market power held by the public insurer in bargaining over prices on consumers behalf, whereas in the benchmark model, prices are set unilaterally by providers.

The current literature on medical insurance and health-care market outcomes emphasizes that under indemnity insurance medical prices are higher than under HMOs (where consumers sort into insurance plans that define exclusive or preferred providers); see, for example, Lyon (1999) and Katz (2011). This occurs because indemnity insurance bundles providers under a single insurance premium; hence, demand is less responsive to unilateral price increases by each of them. The present results show similar implications of bundling medical products under a single insurance policy even when consumers have significant market power through the representation of the public insurer and are offered not only higher prices but also product choices that decrease consumers' surplus.

The (more general) literature on common agency showed that selling competing products through a common retailer may alleviate the extend of competition between producers and facilitate collusion; see Bernheim and Winston (1985) and Gal-Or (1991). ${ }^{6}$ In the context of the present work, the public insurer may be considered as a common agent that distributes medical products to consumers. However, in contrast to the common agency literature that studied distribution of competing products in spot markets, the current analysis focuses

5 In the context of health-care markets, the analysis of sequential moves may be of special relevance to the debate on the welfare implications of follow-on drugs, also known as "me-too" drugs. As phrased recently in "Forbes" magazine: "They may have some unique niche in the market, but they are fairly redundant with other therapies that are already available. Many of these you could call me-too drugs.” The full article is available at http://www.forbes.com/sites/ johnlamattina/2015/01/19/im.pact-of-me-too-drugs-on-health-care-costs/. For more on followon drugs, see DiMasi and Paquette (2004).

6 I am grateful to the referee of this journal for highlighting this relation to the literature on common agency. 
on option market sales where the two products are perceived as complements by consumers, and as such they are bundled under single insurance policy. Hence, the exact role of medical insurers as a common agent in health-care markets deserves further investigation that exceeds the scope of this study.

The current analysis of option demand markets yields distinctive results compared with the respective spot market outcomes because option demand sales and spot demand sales induce different types of competition between medical providers. In spot markets, providers compete over the exclusive purchase of the marginal consumer, as each consumer buys from only one provider. In the option market, providers compete over marginal inclusion under insurance coverage, where the marginal consumer is buying the option to gain access to both of them.

Hence, providers that are perceived as substitutes in the spot market may be perceived as complements in the option market, if product differentiation justifies the additional insurance premium payment. In spot market competition, providers aim to "steal" the marginal consumer from one another by making their products attractive for treating the consumers' specific medical need. When they sell insurance, they aim to maximize the option value of their products in treating all possible conditions of the marginal consumer, who eventually buys insurance for both products. In the benchmark model, under symmetric equilibrium, providers' incentive to maximize the option value of their products coincides with market welfare maximization.

More formally, the different market outcomes for competition in option demand and spot markets can be related to the different response functions that prevail in their location sub-game stage. In the current analysis, these response functions are downward sloping, whereas in the corresponding spot market, the best response functions in the location stage imply maximal differentiation regardless of the opponent choice. Gal-Or (1985) showed that whether the sequential moves of identical players yield a first-mover advantage or disadvantage depends on the slope of the response function: a downward-sloping response function implies a first-mover advantage, as in the current analysis, and a flat response function (as in the spot market case) implies profit neutrality with respect to providers' order of moves. ${ }^{7}$

The remainder of the paper is organized as follows: Section 2 presents the detailed setup of the study. Section 3 studies competition and product choices in the benchmark model of option demand markets. Section 4 examines competition and product choices in option demand markets under public insurance, and Section 5 concludes the paper.

$7 \mathrm{I}$ am grateful to the referee of this journal for pointing out this inference. 


\section{The Benchmark Model}

I study Hotelling's linear market for differentiated medical products. The market is populated with a unit mass of consumers indexed $i$ who are ex ante identical with respect to their medical needs: each consumer faces the probability $\pi$ of becoming sick with a medical need $x_{i}$ that is drawn from a uniform distribution over the unit interval $x \sim U[0,1]$. The distribution $x$ is common knowledge. Upon the emergence of a medical condition, the sick consumer is correctly diagnosed at no cost, and her medical need becomes common knowledge.

There are two medical providers indexed: $j=\{1,2\}$. Each provider privately chooses variety in the unit interval $y_{i} \in(0,1)$. Then each provider chooses price $p_{j}$. The marginal cost of provision is normalized to zero. Perfectly competitive insurers price and sell separate insurance policies for each product. I assume full reimbursement, implying that the price $p_{j}$ translates into an actuarially fair premium denoted $o p_{j} \equiv \pi_{j} p_{j}$, where $\pi_{j}$ is consumers' probability of utilizing product $j$. When buying insurance for product $j$, only $\pi_{j}=\pi$. When buying insurance policies for both products, $\pi_{j}$ is the probability that product $j$ will be utilized by an ex ante healthy consumer. Then, $\pi_{j}$ depends on the locations of the two products on the variety interval and the distribution of medical needs. To simplify exposition, I will describe the provider's pricing choice in terms of the insurance premiums - that is, the option price op.

The healthy consumer enjoys a reservation utility $v$. When the sick consumer's utility decreases to zero if not treated, then once she is treated, it depends on the effectiveness of the utilized medical product. The effectiveness of a medical product is decreasing with horizontal distance from the treated medical need. Hence, the expected utility from using product $y_{j}$ for treating medical need $x_{i}$ is

$$
E\left[u\left(x_{i}, y_{j}\right)\right]=(1-\pi) v+\pi\left[v-\theta\left(x_{i}-y_{j}\right)^{2}\right]
$$

and the expected utility from buying insurance for utilizing product $y_{j}$ only is

$$
E\left[u\left(x, y_{j}\right)\right]=(1-\pi) v+\pi \int_{0}^{1}\left[v-\theta\left(x-y_{j}\right)^{2}\right] d x-o p_{j}
$$

The expected utility function [1] is conventional in the reference literature. ${ }^{8}$ It implies neutrality with respect to the financial risk associated with medical expenses. Abstracting from risk aversion greatly simplifies the analysis, but adding risk aversion should not alter the main results. The parameter $\theta$

8 See, for example, Gal-Or (1997), Lyon (1999) and Douven et al. (2014). 
measures the degree of differentiation over medical conditions or the cost of mismatch between medical needs and treatments, which is not insurable. ${ }^{9}$

The analysis proceeds in four stages: (1) Each provider chooses variety in the product interval. (2) Providers set prices for their products. (3) Consumers decide whether to buy insurance for only one (preferred) product or for both. (4) Medical conditions are realized, consumers utilize the preferred medical products (under insurance coverage) and providers are reimbursed.

\section{Equilibrium}

\subsection{Simultaneous Entry}

I start by studying variety-price choices in simultaneous moves. Narrowing my attention to symmetric equilibria, I assume $y_{1} \in\left[0, \frac{1}{2}\right]$ and $y_{2} \in\left[\frac{1}{2}, 1\right]$. The consumer's expected utility from having only one variety under insurance coverage is denoted as $O_{j}$, with $j=\{1,2\}$, and the consumer's expected utility from having both varieties under coverage is denoted as $O_{1+2}$.

To build an intuitive argument for the formal analysis that follows, consider a case in which both varieties are equally priced and symmetrically located on the product line. Consumers would want to buy insurance for both varieties only if the additional premium payment justifies the increase in expected therapeutic effectiveness. If the products are only slightly differentiated, then only a correspondingly low price would justify buying insurance for both. However, if prices are not that low, then the two providers are engaged in fierce price competition, a la Bertrand. This occurs because they have the same stand-alone option value: symmetrically located and equally priced, the two products are perceived as perfect substitutes by the ex ante identical consumers.

Hence, the demand faced by each provider is extremely elastic for high prices: each provider can "steal" the entire market by marginally reducing its rival's price. Eventually, demand becomes perfectly inelastic once both products are included under insurance coverage. Then, demand cannot increase with further price reductions as the market is saturated. As all consumers in the insurance market are identical, this implies that in equilibrium, they all buy insurance for both products. This equilibrium condition is formally presented in the following lemma.

9 I assume $\frac{4 v}{5 \theta}>1$ to assure a fully served market and to ensure that all product utilizations are beneficial at a price of zero. 
Lemma 1: Equilibrium prices must satisfy $O_{1+2}=O_{2}=O_{1}$.

Proof: $\forall O_{1} \geq O_{2}>O_{1+2}, \exists o p_{2}{ }^{\prime} \equiv o p_{1}-\varepsilon$, such that $O_{2}>O_{1}>O_{1+2}$, where $\varepsilon$ is arbitrarily small. Thus, in equilibrium, $O_{1+2} \geq O_{1}$ and $O_{1+2} \geq O_{2}$. Profit maximization implies that providers will set their prices to satisfy both conditions with equality.

Lemma 1 states that in equilibrium, consumers are indifferent between having either or both products under insurance coverage (I assume that they buy insurance for both). The equilibrium is solved backward, starting with the price competition sub-game. According to Lemma 1 , as long as $O_{1} \geq O_{2}>O_{1+2}$ or $O_{1} \geq O_{2}>O_{1+2}$ providers are engaged in fierce price competition that reduces one another's prices. Provider 1 has no further incentive to lower the price $o p_{1}$ once $\mathrm{O}_{2} \leq \mathrm{O}_{1+2}$; then, consumers prefer having both products under coverage rather than having insurance for product 2 only.

This condition can be written explicitly as

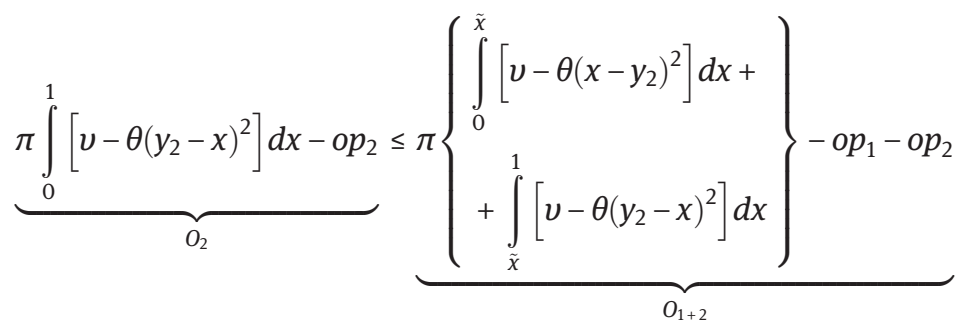

The integral limit $\tilde{x}=\frac{y_{1}+y_{2}}{2}$ is the fraction of sick consumers who would prefer, $e x$ post, being treated by provider 1 when both products are under insurance coverage. Rearranging and elaborating eq. [2] yields the following upper bound for $o p_{1}$ in equilibrium:

$$
o p_{1} \leq \pi \theta\left\{\int_{0}^{\frac{y_{1}+y_{2}}{2}}\left[y_{2}^{2}-y_{1}^{2}-2 x\left(y_{2}-y_{1}\right)\right] d x\right\}=\frac{\pi \theta}{4}\left(y_{1}+y_{2}\right)^{2}\left(y_{2}-y_{1}\right)
$$

When ensuring equality, condition [2a] defines the equilibrium limit option price $o p_{1}$ given the locations of both providers on the product line. In the first stage of the game, provider 1 chooses its optimal variety-denoted $y_{1}^{\star}$-to maximize eq. [2a] following the first-order condition

$$
y_{1}^{*}=\frac{y_{2}}{3}
$$


Proposition 1: The simultaneous game has a unique equilibrium symmetric with efficient horizontal differentiation: $y_{1}^{\star}=\frac{1}{4}, y_{2}^{\star}=\frac{3}{4}$.

Proof: Imposing symmetry in eq. [3] yields $y_{1}^{\star}=\frac{1}{4}, y_{2}^{\star}=\frac{3}{4}$.

In equilibrium, the option price and profit for each provider are $o p^{\star}=\frac{\pi \theta}{8}$, and consumers' expected utility is $E(U)=v-\pi \theta \cdot \frac{13}{48} \approx v-0.27 \pi \theta$. Note that the response function [3] implies that if provider 2 is more aggressive, i. e., targeting a larger market share by locating closer to 1, then provider 1 finds it optimal to give up further market share and relocate away from 2. In this sense that eq. [3] can be interpreted as downward sloping and based on Proposition 1, it supports interior solution for the location sub-game. By comparison, in the respective spot market competition, maximal differentiation is always the optimal response (see the Appendix for formal exposition).

\subsection{Sequential Entry}

Suppose now that provider 2 has the opportunity to choose variety first. Next, provider 1 enters the market by choosing variety, and then they both compete in prices, as in Section 3.1 (still assuming that $y_{2} \geq y_{1}$ ). Based on Lemma 1, for a given variety choice and option price set by the leader, the option value of the follower's product must still satisfy eq. [2]. Therefore, the optimal variety choice for the follower should still satisfy condition [3] $y_{1}^{\star}=\frac{y_{2}}{3}$. Then, the equilibrium condition $\mathrm{O}_{1+2} \geq \mathrm{O}_{2}$ implies the following option value for the leader, accounting for the follower's response function:

$$
\pi\left\{\begin{array}{l}
\int_{0}^{\tilde{x}}\left[v-\theta\left(x-\frac{y_{2}}{3}\right)^{2}\right] d x+ \\
+\int_{\tilde{x}}^{1}\left[v-\theta\left(y_{2}-x\right)^{2}\right] d x
\end{array}\right\}-o p_{1}-o p_{2} \geq \pi \int_{0}^{1}\left[v-\theta\left(x-\frac{y_{2}}{3}\right)^{2}\right] d x-o p_{1}
$$

where $\tilde{x}=\frac{y_{2}+y_{1}}{2}=\frac{1}{2}\left(y_{2}+\frac{y_{2}}{3}\right)=\frac{2}{3} y_{2}$. Rearranging and elaborating condition [4] yields the following explicit form:

$$
o p_{2} \leq \pi \theta\left[\left(\frac{2 y_{2}}{3}\right)^{3}-2\left(\frac{2 y_{2}}{3}\right)^{2}+\frac{2 y_{2}}{3}\right]
$$


Proposition 2: Sequential entry results in asymmetric equilibrium: the leader locates at the market center, and the follower is close to the market end.

Proof: Maximizing eq. [4a] with respect to $y_{1}$ yields the quadratic equation $4 y_{2}^{2}-8 y+3=0$ with the single feasible root $y_{2}^{\star}=\frac{1}{2}$; hence, $y_{1}^{\star}=\frac{1}{6}$.

Note that horizontal differentiation here is inefficient: it is lower than that under simultaneous moves and asymmetric. However, the equilibrium option prices (and profits) are $o p_{2}^{\star}=\frac{4 \pi \theta}{27}, o p_{2}^{\star}=\frac{\pi \theta}{27}$, and consumers' expected utility is $E(U)=v-\pi \theta \frac{7}{27} \approx v-0.26 \pi \theta$. Comparing these values with the corresponding values from the previous section shows that sequential entry yields first-mover gains to the leader and increases consumers' expected utility.

Recall that the best response function in the location sub-game defined by eq. [3] is downward sloping in the opponent's market share choice, and thus, the first-mover advantage presented in Proposition 2 is consistent with Gal-Or's (1985) results. In the respective spot market competition, maximal differentiation is always optimal, implying flat (zero-slope) response functions. In this case, consistent with Gal-Or's (1985) study, providers' product choice and profits are neutral to entry timing, as noted by Tabuchi and Thisse (1995).

\subsection{Quality Choice}

In this section, I add to the analysis of vertical differentiation through costly product quality choices. With product quality denoted as $q_{j}$, I conventionally modify the expected utility function $[1]^{10}$ :

$$
E\{U\}=(1-\pi) v+\pi \int_{0}^{1}\left[v+q_{j}-p_{j}-\theta\left(y_{j}-x\right)^{2}\right] d x
$$

I assume that the provision of quality is subject to a quadratic cost function, which is fixed with respect to the output level:

$$
C\left(q_{j}\right)=\frac{\mu}{2} q_{j}^{2}
$$

I also assume that $\theta>\frac{\pi}{\mu}$ to ensure nonnegative profit in equilibrium. I solve a two-stage game in simultaneous moves: product variety and quality are chosen in the first stage, and price competition prevails in the second stage. ${ }^{11}$ The

10 See, for example, Lyon (1999), Katz (2011) and Bardey, Cantac, and Lozachmeur (2012). 11 A three-stage game - variety $\rightarrow$ quality $\rightarrow$ price - yields the same result with less tractable derivation. 
equilibrium prices are still subject to Lemma 1 . When we consider utility from quality, condition [2] becomes

$$
\pi\left\{\begin{array}{l}
\int_{0}^{\tilde{x}}\left[v+q_{1}-\theta\left(x-y_{1}\right)^{2}\right] d x \\
+\int_{\tilde{x}}^{1}\left[v+q_{2}-\theta\left(y_{2}-x\right)^{2}\right] d x
\end{array}\right\}-o p_{1}-o p_{2} \geq \pi \int_{0}^{1}\left[v+q_{2}-\theta\left(y_{2}-x\right)^{2}\right] d x-o p_{2}
$$

where $\tilde{x}=\frac{1}{2}\left[\frac{q_{1}-q_{2}}{\theta\left(y_{2}-y_{1}\right)}+y_{1}+y_{2}\right]$ is still the fraction of consumers who choose (ex post) to be treated by provider 1 when both providers are under insurance coverage. Elaborating and rearranging eq. [7] yields the following simplified expression:

$$
o p_{1} \leq \pi\left\{\int_{0}^{\tilde{x}}\left[\left(v+q_{1}-\theta\left(x-y_{1}\right)^{2}\right)-\left(v+q_{2}-\theta\left(y_{2}-x\right)^{2}\right)\right] d x\right\}
$$

Integrating eq. [7a] and subtracting the quality cost, I obtain the expected profit for provider 1:

$$
\pi\left\{\left[q_{1-} q_{2}+\theta\left(y_{2}^{2}-y_{1}^{2}\right)\right] \tilde{x}-\theta \tilde{x}^{2}\left(y_{2}-y_{1}\right)\right\}-\frac{\mu}{2} q_{1}^{2}
$$

Finally, plugging $\tilde{x}=\frac{1}{2}\left[\frac{q_{1}-q_{2}}{\theta\left(y_{2}-y_{1}\right)}+y_{1}+y_{2}\right]$ in eq. [8] yields the following profit function:

$$
\frac{\pi}{4} \frac{\left[\left(q_{1}-q_{2}\right)+\theta\left(y_{2}^{2}-y_{1}^{2}\right)\right]^{2}}{\theta\left(y_{2}-y_{1}\right)}-\frac{\mu}{2} q_{1}^{2}
$$

Proposition 3: There exists a unique symmetric equilibrium with efficient horizontal differentiation and quality provision.

Proof: Differentiating eq. [8a] for $q_{1}$ and $y_{1}$ yields the following first-order conditions:

$$
\begin{aligned}
\frac{\mu}{\pi} q_{1}^{\star} & =\frac{1}{2}\left[\frac{\left(q_{1}^{\star}-q_{2}\right)}{\theta\left(y_{2}-y_{1}\right)}+y_{2}+y_{1}\right] \\
y_{1}^{\star} & =\frac{1}{4}\left[\frac{\left(q_{1}^{\star}-q_{2}\right)}{\theta\left(y_{2}-y_{1}\right)}+y_{2}+y_{1}\right]
\end{aligned}
$$

Imposing symmetry on both conditions yields $q_{1,2}=\frac{\pi}{2 \mu}, y_{1}=\frac{1}{4}, y_{2}=\frac{3}{4}$. The expected market welfare, denoted $W$, with symmetric product choices is 


$$
W=2\left[\pi \int_{0}^{\frac{1}{2}}\left[v+q_{1}-\theta\left(x-y_{1}\right)^{2}\right] d x-\frac{\mu}{2} q_{1}^{2}\right]
$$

Maximizing eq. [9a] with respect to $y_{1}$ and $q_{1}$ yields the first-order conditions $y_{1}=\frac{1}{4}$ and $q_{1,2}=\frac{\pi}{2 \mu}$. Hence, the socially optimal product and quality choices coincide with the equilibrium choices.

The Appendix shows that in the respective spot market, the principle of maximum differentiation still holds, and the quality provided is $q_{1,2}^{S}=\frac{\pi}{3 \mu}$, which is higher than the efficient level and that provided in the option demand market analyzed here. ${ }^{12}$

\section{Public Insurance}

This section extends the benchmark setup by elaborating a more realistic insurance market structure: a single public insurer that bargains over prices with both providers before bundling their services under a single insurance policy that is offered to consumers. Such dominant public insurance plans, such as Medicare in the USA, are common in developed economies. This preliminary extension aims to demonstrate how a more realistic option demand market performs relative to the benchmark model of "pure" option demand markets presented thus far.

\subsection{Simultaneous Entry}

Consider the simultaneous entry game described in Section 3.1 and assume that in the second stage of the game, prices are set through simultaneous Nash bargaining between both providers and the public insurer. ${ }^{13}$ Then, the bargaining solution prices are translated by the public insurer into an actuarially fair insurance premium, denoted pr.

If, for example, only provider 2 is eventually under insurance coverage, the insurance premium is $\mathrm{pr}_{2}=\pi p_{2}$, and the consumer's expected utility is

12 Economides (1989) showed that the principle of maximum differentiation holds in a similar model with quality choice and linear transportation costs.

13 Gal-Or (1997) studied such multilateral bargaining with two (for-profit) competing insurers and two providers. 


$$
O_{2}=(1-\pi) v+\pi \int_{0}^{1}\left[v-\theta\left(y_{2}-x\right)^{2}\right] d x-\pi p_{2}
$$

If both providers are included under the public insurance coverage, the premium is $\operatorname{pr}_{1+2} \equiv \pi\left[\tilde{x} p_{1}+(1-\tilde{x}) p_{2}\right]$, where $\tilde{x}=\frac{y_{1}+y_{2}}{2}$ is the fraction of sick consumers who would prefer (ex post) being treated by provider 1. In this case, the consumer's expected utility is

$$
O_{1+2}=(1-\pi) v+\pi\left\{\begin{array}{l}
\int_{0}^{\tilde{x}}\left[v-\theta\left(x-y_{1}\right)^{2}\right] d x+ \\
+\int_{\tilde{x}}^{1}\left[v-\theta\left(y_{2}-x\right)^{2}\right] d x
\end{array}\right\}-\pi\left[\tilde{x} p_{1}+(1-\tilde{x}) p_{2}\right]
$$

The gain for consumers from adding provider 1 under insurance coverage, given that provider 2 is already included, is

$$
O_{1+2}-O_{2}=\pi \theta\left\{\int_{0}^{\tilde{x}}\left[y_{2}^{2}-2 x y_{2}-y_{1}^{2}+2 x y_{1}\right] d x\right\}-\pi \tilde{x}\left(p_{1}-p_{2}\right)
$$

and the expected surplus for provider 1 is

$$
P S_{1}=\pi p_{1} \tilde{x}
$$

Hence, with equal bargaining power given to the insurer and each provider, the Nash bargaining solution should maximize the product function

$$
\pi\left(p_{1} \tilde{x}\right)\left(\theta\left\{\int_{0}^{\tilde{x}}\left[y_{2}^{2}-2 x y_{2}-y_{1}^{2}+2 x y_{1}\right] d x\right\}-\tilde{x} p_{1}+\tilde{x} p_{2}\right)
$$

The first-order condition yields the optimal price:

$$
p_{1}^{\star}=\frac{\frac{\theta\left(y_{2}^{2}-y_{1}^{2}\right)}{2}+p_{2}}{2}
$$

Applying a similar calculation for provider 2 yields the corresponding optimal price

$$
p_{2}^{\star}=\frac{\theta\left(y_{2}-y_{1}\right)\left[1-\frac{\left(y_{1}-y_{2}\right)}{2}\right]+p_{1}}{2}
$$


Inserting eq. [14a] into eq. [14] and back into eq. [12] yields optimal prices as a function of product choices

$$
\begin{aligned}
& p_{1}^{\star}=\frac{\theta\left(y_{2}-y_{1}\right)\left(\frac{y_{2}+y_{1}}{2}+1\right)}{3} \\
& p_{2}^{\star}=\frac{\theta\left(y_{2}-y_{1}\right)\left[2-\frac{\left(y_{1}+y_{2}\right)}{2}\right]}{3}
\end{aligned}
$$

and providers' surpluses as functions of product choices are

$$
\begin{gathered}
P S_{1}=\pi \tilde{x} p_{1}^{*}=\frac{\pi \theta \frac{y_{2}+y_{1}}{2}\left(y_{2}-y_{1}\right)\left(\frac{y_{2}+y_{1}}{2}+1\right)}{3} \\
P S_{2}=\pi(1-\tilde{x}) p_{2}=\frac{\pi \theta\left(1-\frac{\left(y_{1}+y_{2}\right)}{2}\right)\left(y_{2}-y_{1}\right)\left[2-\frac{\left(y_{1}+y_{2}\right)}{2}\right]}{3}
\end{gathered}
$$

Deriving the first-order condition for maximizing eq. [16] and imposing symmetry, I obtain the equilibrium locations and prices:

$$
p_{1,2}^{*}=\frac{3 \theta}{8}, \quad y_{1}^{*}=\frac{1}{8}, \quad y_{2}^{*}=\frac{7}{8}
$$

Proposition 4: In the market with a public insurer that bundles medical providers under a single insurance policy, the result of simultaneous moves is excessive horizontal differentiation and higher medical prices relative to the benchmark model with separate insurance sales.

Proof: Compare eq. [17] with the results summarized in Proposition 1 for the benchmark model.

Proposition 4 presents an extensive implication of the effect of bundling provider services under a single insurance policy. It shows that when medical products are bundled under a single insurance policy, even a public monopolistic insurer that negotiates over prices on behalf of consumers cannot give consumers the utility level that they would obtain when medical products are sold under separate insurance policies and all market power is obtained by providers. This outcome is due to both higher prices and excessive product differentiation. The consumer's exact expected utility in this market is $E\{U\}=v-\pi \theta \frac{79}{192} \approx v-0.41 \pi \theta$, and the producer's surplus is $P S_{1,2}=\frac{3 \pi \theta}{16}$, which is greater than in the benchmark model but smaller than in the respective spot market (see the Appendix). 


\subsection{Sequential Entry}

Under sequential entry, with provider 2 moving first, eqs [14]-[16] still hold. Maximizing eq. [16] with respect to $y_{1}$ yields the followers' response function:

$$
y_{1}^{*}=\frac{\sqrt{\left(y_{2}+2\right)^{2}+3 y_{2}^{2}}-\left(y_{2}+2\right)}{3}
$$

The response function [18] is increasing with $y_{2}$, as in the response function [3] for the benchmark model. Reinserting eq. [18] into eq. [16a] yields a surplus of the market leader as a function of her product choice only:

$$
P S_{2}=\frac{\pi \theta}{324}\left(8-\sqrt{\left(y_{2}+2\right)^{2}+3 y_{2}^{2}}-2 y_{2}\right) \text {. }
$$

Proposition 5: In the market with a public insurer that bundles medical providers under a single insurance policy, sequential entry results in asymmetric equilibrium with the market leader located near the market center and the follower located near the market end.

Proof: It is difficult to derive a closed-form solution for the product choice that maximizes eq. [18a]. However, Figure 1 presents the shape of eq. [17a], showing that it is maximized at $y_{2}^{\star} \approx 0.55$. Thus, by eq. [18], the follower's product choice is $y_{1}^{\star} \approx 0.057$.

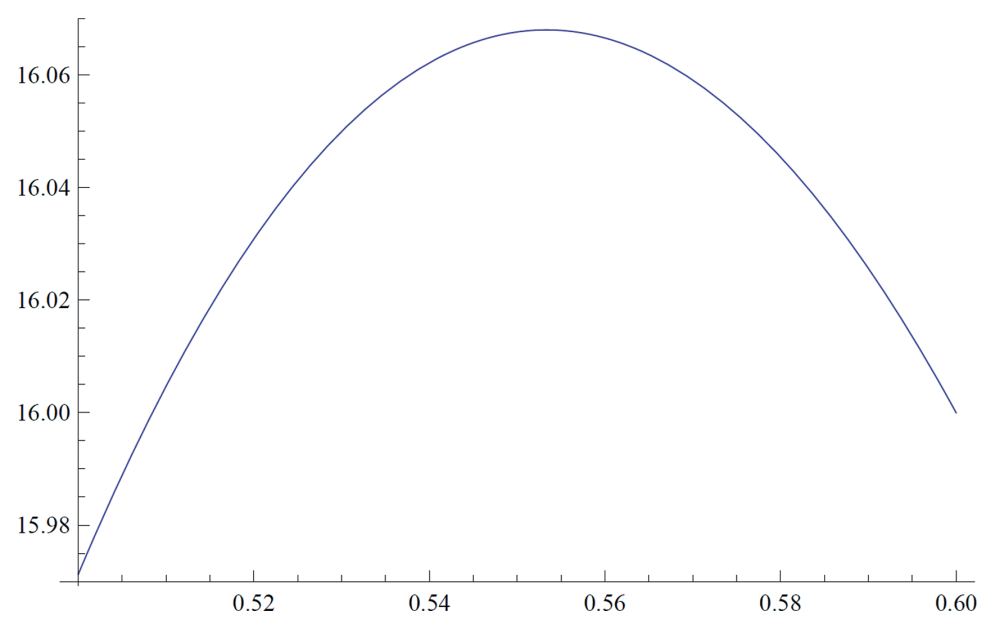

Figure 1: Market leaders' product choice under public insurance. 
The corresponding equilibrium prices are $p_{1}^{\star} \approx \theta \cdot 0.21$ and $p_{2}^{\star} \approx \theta \cdot 0.28$; hence, in accordance with the analysis of the benchmark model, in the market with public insurance, medical prices are lower under sequential moves as presented in eq. [17]. In comparison with the results presented under sequential entry in the benchmark model (Section 3.2), product choices are qualitatively similar; however, differentiation is higher (half under public insurance compared with one-third in the benchmark model), and medical prices are higher.

Furthermore, under the public insurance regime, the timing of entry does not affect prices that much, whereas in the benchmark model, the price of the leader is four times greater than the price of the follower. However, under the public insurance regime, the market leader still has significant first-mover gains by capturing more than two-thirds of the market through central product positioning. Finally, consumers' expected utility here is $E(U) \approx v-0.35 \pi \theta$. It is higher than in the case of simultaneous entry under public insurance but lowers than in the benchmark model with sequential entry.

\subsection{Quality Choice}

Adding quality choice to the analysis of public insurance regime, I still follow the preferences and quality cost specifications presented in eqs [5] and [6]. Repeating the calculations in eqs [10]-[15] for the utility function [5] yields the following price equation for provider 1 :

$$
p_{1}^{\star}=\frac{\theta\left(y_{2}-y_{1}\right)\left[\frac{1}{2}\left[\frac{3\left(q_{1}-q_{2}\right)}{\left(y_{2}-y_{1}\right) \theta}+y_{1}+y_{2}\right]+1\right]}{3}
$$

The corresponding profit equation is

$$
\psi=P S_{1}-C\left(q_{1}\right)=\pi \frac{\left[\frac{1}{4}\left[\frac{3\left(q_{1}-q_{2}\right)}{\left(y_{2}-y_{1}\right) \theta}+y_{1}+y_{2}\right]+1\right]\left[\left(q_{1}-q_{2}\right)+\theta\left(y_{2}^{2}-y_{1}^{2}\right)\right]}{3}-\frac{\mu}{2} q_{1}^{2}
$$

where $P S_{1}=\pi p_{1}^{\star} \tilde{x}$, and $\tilde{x}=\frac{1}{2}\left[\frac{q_{1}-q_{2}}{\theta\left(y_{2}-y_{1}\right)}+y_{1}+y_{2}\right]$.

Proposition 6: In the market with a public insurer that bundles medical providers under a single insurance policy, horizontal differentiation is excessive, quality provision is lower and prices are higher compared with the benchmark model.

Proof: Maximizing eq. [20] with respect to $y_{1}$ and $q_{1}$ and imposing symmetry yields $y_{1}^{\star}=\frac{1}{8}, y_{2}^{\star}=\frac{7}{8}, q_{1,2}^{\star}=\frac{5 \pi}{16 \mu}$. This implies that the profit is positive for $\theta \mu-\frac{\pi 5}{32}$. 
Based on eq. [19], under these symmetric product choices, equilibrium prices are the same as in eq. [17]: $p_{1,2}^{\star}=\frac{3 \theta}{8}$.

Proposition 6 follows Proposition 4 in demonstrating the negative effect of bundling medical providers under a single insurance policy on consumers. This occurs because of excessive product differentiation, lower quality and higher prices. The consumers expected utility is $E(U) \approx v+\frac{5 \pi}{16 \mu}-0.41 \pi \theta$. Under the public insurance regime, quality provision is also lower than the level that would be provided in the respective spot market, and the consumers expected utility under public insurance is always higher considering the positive profit requirements. ${ }^{14}$ Table 1 presents a comparative summary of the results from the two analyses of competition and competition option demand markets with quality choice (from this section and Section 3.3).

Table 1: Product choice and prices - results summary.

\begin{tabular}{lccc}
\hline & $\boldsymbol{q}$ & $\Delta \mathbf{y}$ & $\boldsymbol{p}_{\boldsymbol{j}}$ \\
\hline Social optimum & $\frac{\pi}{2 \mu}$ & $\frac{1}{2}$ & - \\
Benchmark model & $\frac{\pi}{2 \mu}$ & $\frac{1}{2}$ & $\frac{\pi \theta}{8}$ \\
Public insurance & $\frac{5 \pi}{16 \mu}$ & $\frac{3}{4}$ & $\frac{3 \theta}{8}$ \\
Spot market & $\frac{\pi}{3 \mu}$ & 1 & $\theta$ \\
\hline
\end{tabular}

\section{Conclusions}

This work presents the first analysis of competition through horizontal and vertical differentiation in option demand markets, which are common in the health-care sector. This study shows that product choices in option demand markets may differ greatly from those in spot markets, and the results highlight the role of bundling medical products under a single insurance policy in softening competition between medical providers. The analysis focuses on two alternative market structures: (a) a "pure" option demand market abstracting various structural characteristics of real insurance markets and (b) a public insurance regime with the public insurer bargaining over price with providers

14 All corresponding calculations for the respective spot market are presented in the Appendix. 
on behalf of consumers before bundling both products under a single insurance policy.

For the benchmark model, I showed that simultaneous entry results in efficient horizontal differentiation and quality provision. Both the quality and variety choices made by providers aim to maximize the option value of their products to consumers, accounting for the cost of quality provision. Hence, in this market, under symmetric equilibrium, providers' private incentives coincide with the objective of welfare maximization.

Then, I showed that under public insurance, horizontal differentiation is excessive, prices are higher, and quality provision is lower compared with the benchmark model. Hence, under the public insurance regime, consumers are worse off, although the public insurer has significant market power and the ability to negotiate prices; by contrast, in the benchmark model, all market power is held by providers. These results call for subsequent research on the motivations for bundling medical products under insurance policies and their implications for market outcomes. In particular, it seems highly relevant to explore this issue in an extended framework with multiple for-profit insurers and providers (as in Gal-Or [1997] and Douven et al. [2014]) under alternative degrees of vertical integration.

The analysis of sequential entry that may be of special relevance to the debate on "me-too" drugs yielded asymmetric equilibrium with the leader located at the market center and the follower located close to the market end, therefore, capturing a smaller market share. Nonetheless, despite the inefficient horizontal differentiation and the niche properties of the followers' products, consumers are better off than they are under the efficient equilibrium obtained under simultaneous moves because of lower equilibrium prices.

A strong assumption employed in this work is that consumers are ex ante identical with respect to expected medical needs and preferred medical providers. This assumption sharpens the analysis by imposing fierce (Bertrand) competition in option prices. Gal-Or (1997) and Douven et al. (2014) employed the same assumption but allowed consumers to differ in their preferences for differentiated insurers, with prices set through multilateral negotiations. In a subsequent paper (Sorek 2015), I let consumers be ex ante identical with respect to their expected medical needs but differentiated with respect to their geographic address, and providers choose both the geographic location and horizontal product differentiation. I find that equilibrium with efficient differentiation in the product space can still be present in this elaborated setup.

Acknowledgments: The author would like to thank Randy Beard, Esther Gal-Or and Aditi Sengupta for their helpful comments, anonymous referee of this 
journal for insightful comments and suggestions, and Adeet Handel for the thought-provoking discussions. I also benefited from participants' comments on presentations at Auburn University, the spring 2014 Midwest-Theory Conference at UIPUI, the ASHE 2014 conference at USC, the IIOC-2015 in Boston as well as from discussion comments by Guy Arie and Ted Frech.

\section{Appendix: Spot Market Competition}

Here, I present the outcomes of duopolistic competition in the spot market, in which providers sell their products to sick consumers, and all other specifications and notations presented in Sections 2-4 are the same. The demand faced by provider $1, D_{1}$, in spot market competition is

$$
D_{1}^{S}=\tilde{\chi}=\frac{1}{2}\left[\frac{p_{2}-p_{1}+q_{1}-q_{2}}{\theta\left(y_{2}-y_{1}\right)}+y_{2}+y_{1}\right]
$$

and the corresponding profit, denoted $\psi$, is

$$
\psi_{1}=P S_{1}^{S}-C\left(q_{1}\right)=\frac{\pi}{2}\left[\frac{p_{2}-p_{1}+q_{1}-q_{2}}{\theta\left(y_{2}-y_{1}\right)}+y_{2}+y_{1}\right] p_{1}-\frac{\mu}{2} q_{1}^{2}
$$

Hence, the profit-maximizing price for provider 1 is

$$
p_{1}^{s}=\frac{1}{2}\left[p_{2}+q_{1}-q_{2}+\theta\left(y_{2}^{2}-y_{1}^{2}\right)\right]
$$

and, based on a similar calculation, the optimal price for provider 2 is

$$
p_{2}^{s}=\theta\left(y_{2}-y_{1}\right)+\frac{p_{1}-\left(q_{1}-q_{2}\right)-\theta\left(y_{2}^{2}-y_{1}^{2}\right)}{2}
$$

Substituting eqs [23] and [24] into one another yields the optimal prices as functions of the product choices from the first stage of the game:

$$
\begin{aligned}
& p_{2}^{s}=\frac{2 \theta\left(y_{2}-y_{1}\right)+\left[q_{1}-q_{2}+\theta\left(y_{2}^{2}-y_{1}^{2}\right)\right]}{3} \\
& p_{2}^{s}=\frac{4 \theta\left(y_{2}-y_{1}\right)-\left[q_{1}-q_{2}+\theta\left(y_{2}^{2}-y_{1}^{2}\right)\right]}{3}
\end{aligned}
$$

Inserting the latter price expressions back into eq. [22] yields

$$
\psi_{1}^{S}=\frac{\pi}{18} \frac{\left[2 \theta\left(y_{2}-y_{1}\right)+q_{1}-q_{2}+\theta\left(y_{2}^{2}-y_{1}^{2}\right)\right]^{2}}{\theta\left(y_{2}-y_{1}\right)}-\frac{\mu}{2} p_{1}^{2}
$$


The first-order conditions for profit maximization are

$$
\begin{array}{r}
\frac{\partial \psi_{1}^{s}}{\partial y_{1}}=0: 4\left(1+y_{1}\right)=2+\frac{q_{1}-q_{2}}{\theta\left(y_{2}-y_{1}\right)}+\left(y_{2}+y_{1}\right) \\
\frac{\partial \psi_{1}^{s}}{\partial q_{1}}=0: \frac{\left[2 \theta\left(y_{2}-y_{1}\right)+q_{1}-q_{2}+\theta\left(y_{2}^{2}-y_{1}^{2}\right)\right]}{9 \theta\left(y_{2}-y_{1}\right)}=\frac{\mu}{\pi} q_{1}^{\star}
\end{array}
$$

Focusing on the first condition and abstracting quality choices, i. e. $q_{1,2}=0$, I obtain the best response function for the optimal location under simultaneous moves in spot market competition: $y_{1}^{\star}=\frac{-2+y_{2}}{3}$, which is negative for the relevant range of values of $y_{2}$. This result also holds for any symmetric quality choice $q_{1}=q_{2}$. Hence, the principle of maximum differentiation applies here as well. Imposing symmetry on the second optimality condition in eq. [28], I obtain $q_{1,2}^{s}=\frac{\pi}{3 \mu}$, which is higher than the efficient quality provision that is provided in the pure option market (under efficient horizontal differentiation). The implied equilibrium profit is positive for $\mu \theta>\frac{\pi}{9}$. Finally, under symmetric equilibrium of maximal (horizontal) differentiation, prices are $p_{1,2}^{s}=\theta$, and producers' surpluses are $P S_{1,2}^{S}=\frac{\pi \theta}{2}$. These values are neutral to any symmetric quality choice, and thus, they also persist when quality choice is not allowed at all, as in Sections 3 and 5. Consumer surplus is $E(U)=v+\frac{\pi}{3 \mu}-\frac{13 \pi \theta}{12}$, and with no quality considerations: $E(U)=v-\frac{13 \pi \theta}{12}$.

\section{References}

Anderson, S. P., J. Goeree, and R. Ramer. 1997. "Location, Location, Location.” Journal of Economic Theory 77:102-27.

Bardey, D., and J. -M. Bourgeon. 2011. "Health Care Network Formation and Policyholders' Welfare.” The B.E. Journal of Economic Analysis \& Policy (Contributions) 11:1935-1682.

Bardey, D., C. Cantac, and J.-M. Lozachmeur. 2012. "The Regulation of Health Care Providers' Payments When Horizontal and Vertical Differentiation Matter." Journal of Health Economics 31:691-704.

Barros, P. P., and X. Martinez-Giralt. 2002. "Public and Private Provision of Health Care." Journal of Economics and Management Strategy 11:109-33.

Bernheim, D. B., and M. D. Winston. 1985. "Common Marketing Agency as a Device for Facilitating Collusion." The RAND Journal of Economics 16:269-81.

Bester, H.. 1998. "Quality Uncertainty Mitigates Product Differentiation." RAND Journal of Economics 29:828-44.

Capps, C., D. Dranove, and M. Satterthwaite. 2003. "Competition and Market Power in Option Demand Markets." RAND Journal of Economics 34:737-63. 
d’Aspremont, C., J. Gabszewicz, and J.-F. Thisse. 1979. "On Hotelling’s "Stability in Competition." Econometrica 47:1145-50.

Douven, R., R. Halbersma, K. Katona, and V. Shestalova. 2014. "Vertical Integration and Exclusive Behavior of Insurers and Hospitals." Journal of Economics \& Management Strategy 23:344-68.

DiMasi, J. A., and C. Paquette. 2004. "The Economics of Follow-On Drug Development: Trends in Entry Rates and the Timing of Development." PharmacoEconomics 22:1-14.

Economides, N. 1986. "Minimal and Maximal Product Differentiation in Hotelling's Duopoly." Economics Letters 21:67-71.

Economides, N. 1989. "Quality Variations and Maximal Variety Differentiation.” Regional Science and Urban Economics 19:21-9.

Gal-Or, E. 1985. "First Mover and Second Mover Advantages." International Economic Review 26:649-53.

Gal-Or, E. 1991. "A Common Agency with Incomplete Information." The RAND Journal of Economics 22:274-86.

Gal-Or, E. 1997. "Exclusionary Equilibria in Health-Care Markets." Journal of Economics \& Management Strategy 6:5-43.

Gaynor, M., K. Ho, and R. J. Town. 2015. "The Industrial Organization of Health Care Markets." Journal of Economic Literature 53:235-84.

Gaynor M., and C. A. Ma. 1996. Insurance, vertical restraints and competition. Unpublished manuscript, US: Carnegie Mellon University. Available at: http://www.andrew.cmu.edu/ user/mgaynor/Assets/exclusive.pdf.

Gaynor, M., and R. J. Town. 2012. "Competition in Healthcare Markets." In Handbook of Health Economics, Volume 2, Chapter 9, edited by T. G. McGuire, M. V. Pauly, and P. Pita Barros, 499-639. Amsterdam and London: Elsevier North-Holland.

Katz, M. L. 2011. "Insurance, Consumer Choice, and the Equilibrium Price and Quality of Hospital.” The B.E. Journal of Economic Analysis \& Policy (Advances) 11:Article 5.

Lyon, T. P. 1999. "Quality Competition, Insurance, and Consumer Choice in Health Care Markets." Journal of Economics \& Management Strategy 8:545-80.

Ma, C. A. 1997. "Option Contracts and Vertical Foreclosure." Journal of Economics \& Management Strategy 6:725-53.

Ma, C. A., and J. F. Burgess Jr. 1993. "Quality Competition, Welfare, and Regulation.” Journal of Economics 58:153-73.

Sorek, G. 2015. “Location and Product Choice in Option Demand Markets.” Auburn University Economics Working Papers. Available at: http://cla.auburn.edu/econwp/Archives/2015/ 2015-11.pdf

Tabuchi, T., and J. -F. Thisse. 1995. "Asymmetric Equilibria in Spatial Competition." International Journal of Industrial Organization 13:213-27.

Town, R., and G. Vistnes. 2001. "Hospital Competition in HMO Networks." Journal of Health Economics 20 (733):752.

Note: An earlier version of this work titled "Health Insurance and Competition in Health Care Markets" was also circulated. 